International Journal of Engineering \& Technology, $7(2.23)(2018)$ 133-136
International Journal of Engineering \& Technology
SPC
Website: www.sciencepubco.com/index.php/IJET
Research paper

\title{
Procedure to Evaluate Current Formation Pressure in Wells with ESP
}

\author{
O.A. Gribennikov ${ }^{1 *}$, L.N. Balandin ${ }^{2}$, V.I. Astafev ${ }^{3}$ \\ ${ }^{1}$ Assoc. Professor, Samara State Technical University, Samara, Russia \\ ${ }^{2}$ Assoc. Professor, Samara State Technical University, Samara, Russia \\ ${ }^{3}$ Professor, Samara State Technical University, Samara, Russia \\ *Corresponding author E-mail: o.a.gribennikov@mail.ru
}

\begin{abstract}
While operating the wells with ESP it's impossible to make the direct measurement of the formation pressure with the use of bottom-hole pressure gauge. That is why they presently use various indirect methods to evaluate formation pressure that are based upon the recalculation of static fluid level in well annulus for the fluid column pressure. The authors consider the procedure to evaluate formation pressure that was designed for the wells equipped with ESP. This procedure is a simple one and enables to perform real-time formation pressure metering. The obtained results have been compared with hydro-dynamic studies and have demonstrated their high convergence.
\end{abstract}

Keywords: Formation Pressure, Dynamic Level, Well Survey, to Bring a Well to Its Production Level, Pumping Well.

\section{Introduction}

The evaluation of the verified formation pressure figures $\left(\mathrm{p}_{\mathrm{i}}\right)$ is a difficult process while operating the wells with artificial lift (wells with ESP). The problem with the evaluation of formation pressure in wells was considered by many authors [1-15]. All the procedures proposed in the above-mentioned papers have found their practical application and provide verified results within some specific accuracy. But in any case they have several drawbacks, and namely:

1. By use of various measurement procedures it is quite possible to evaluate the formation pressure only in natural flowing and gaslift wells and these wells are quite difficult in operation within the whole number of wells with artificial lift.

2. All the methods provides for the prematurely production well shut-down during the periods of well maintenance and the performance of well survey jobs take some long time.

3 . The methods to evaluate formation pressure during the operation of wells with artificial lift have significant inaccuracy resulting from the use of fluids with varying densities inside the borehole, that is also calculated using various methods [16-24].

4. Some specific procedures are operable until they reach the specific level of water-cut in produced well product.

5. Some procedures were designed for the specific field and productive reservoir conditions.

The present paper considers the procedure to evaluate formation pressure through the use of curves at the stage of bringing a well to a stable production level and this procedure is peculiar for its simplicity and authenticity. The procedure is based up on the processing of data on dynamic level changes that were obtained during the stable of well bringing to a production level. It is applicable only for the wells that were previously killed for routine servicing or well work-over operations and only for those wells that are equipped with electric submersible centrifugal pumps (ESP).
The procedure was field-tested at some oil fields of Samara Region.

\section{Methodology}

The process of bringing a well to a stable production level includes several stages. At stage 1 there is the linear decrease of fluid dynamic level in the annulus (no fluid inflow observed). At stage 2 there is the inflow of reservoir fluid and there is the break of the curve showing the process of bringing a well to production level, i.e. tangent slope ratio (velocity of dynamic fluid level change)of the curve starts changing.

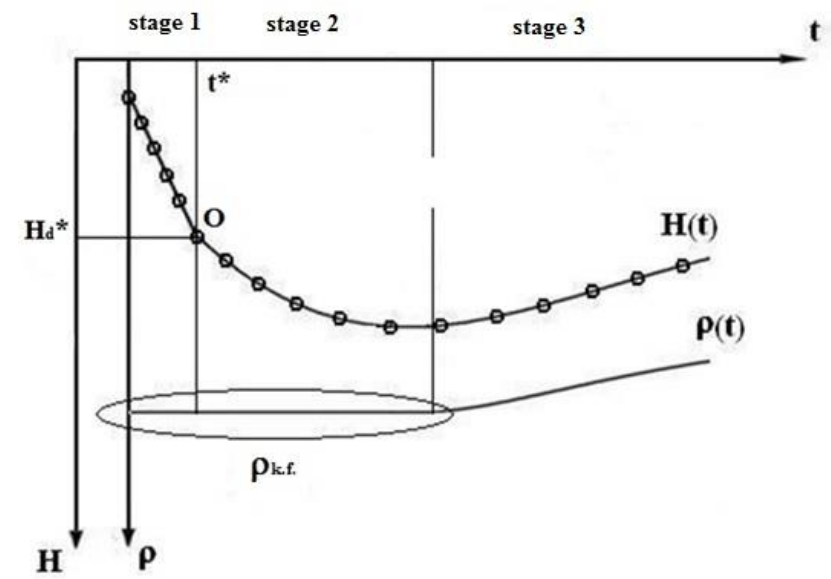

Fig. 1: Curve Showing the Change in Dynamic Level and Well Fluid Density At the Stage of Brining a Well to Stable Production Level

At stage 3 the dynamic level in a well is increasing due to replacement of well-kill fluid in annulus by reservoir oil. Paper [25] illustrates that the fluid density in a well is constant and is equal to 
well-kill fluid density, and this starts decreasing from stage 3 (Fig. $1)$.

Therefore it's possible to make the conclusion that the pressure constituted by the hydrostatic well pressure in the annulus (prior to start of stage 3 during the process of bringing a well to production level the annulus pressure was equal to 0 , as there is no gas in the fluid mixture pumped-out from a well), and at point 0it's compared with formation pressure (reservoir fluid inflow is possible in conditions of draw-down, i.e. at $\left.\mathrm{P}_{\mathrm{w}}<\mathrm{P}_{\mathrm{i}}\right)$. Hence, formation pressure is defined using equation 1 :

$\mathrm{p}_{i}=\rho_{\mathrm{k} . \mathrm{f}} \cdot \mathrm{g} \cdot\left(\mathrm{H}_{\mathrm{r}}-\mathrm{H}_{\mathrm{d}}^{*}\right)$

Moreover, it's very difficult to register the exact time of transition from dynamic level linear metering to non-linear metering. So, in order to increase the accuracy in locating point 0 it is proposed to act as follows: to plot the straight line 1 using two points to a place with line break (points 1 and 2) and straight line 2 after it (points 3 and 4), and their intersection will give us point 0 (see Fig. 2).

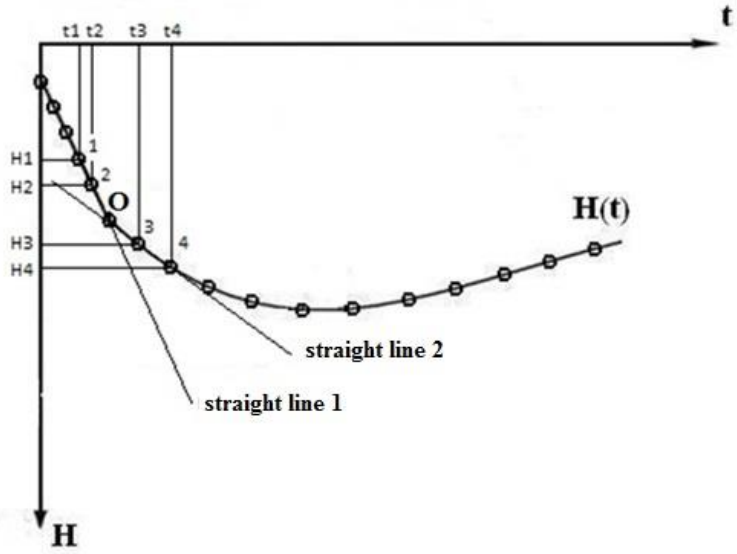

Fig. 2: Method to Locate Break Point Using the Curve at the Stage Of Brining a Well to Production Level

In this case the value of inflow time $t^{*}$ is defined analytically. Point 1 has the following coordinates $\left(\mathrm{t}_{1} ; \mathrm{H}_{1}\right)$, point $2-\left(\mathrm{t}_{2} ; \mathrm{H}_{2}\right)$, point $3-\left(\mathrm{t}_{3} ; \mathrm{H}_{3}\right)$, point $4-\left(\mathrm{t}_{4} ; \mathrm{H}_{4}\right)$.

The equations for the straight lines are presented as: $\frac{H_{1}(t)-H_{1}}{H_{2}-H_{1}}=\frac{t-t_{1}}{t_{2}-t_{1}}$
$\frac{H_{2}(t)-H_{3}}{H_{4}-H_{3}}=\frac{t-t_{3}}{t_{4}-t_{3}}$

By making some mathematical transformations we get the system of equations:

$\left\{\begin{array}{l}H_{1}(t)=\frac{t-t_{1}}{t_{2}-t_{1}} \cdot\left(H_{2}-H_{1}\right)+H_{1} \\ H_{2}(t)=\frac{t-t_{3}}{t_{4}-t_{3}} \cdot\left(H_{4}-H_{3}\right)+H_{3}\end{array}\right.$.

In order to find the common point for the given equations it is required to equate them and find the time. The time of inflow $t *$ start is equal to:

$\mathrm{t}^{*}=\frac{\frac{\mathrm{t}_{1} \cdot\left(\mathrm{H}_{2}-\mathrm{H}_{1}\right)}{\mathrm{t}_{2}-\mathrm{t}_{1}}-\mathrm{H}_{1}-\frac{\mathrm{t}_{3} \cdot\left(\mathrm{H}_{4}-\mathrm{H}_{3}\right)}{\mathrm{t}_{4}-\mathrm{t}_{3}}+\mathrm{H}_{3}}{\frac{\mathrm{H}_{2}-\mathrm{H}_{1}}{\mathrm{t}_{2}-\mathrm{t}_{1}}-\frac{\mathrm{H}_{4}-\mathrm{H}_{3}}{\mathrm{t}_{4}-\mathrm{t}_{3}}}$

The resulted value of $t^{*}$ as per formula (5) is used in any equation of the system (4) and we get the dynamic level at which the reservoir fluid $\mathrm{H}_{\mathrm{d}}{ }^{*}$ inflow starts to appear. After finding $\mathrm{H}_{\mathrm{d}}{ }^{*}$ we make the calculation of formation pressure $\mathrm{p}_{\mathrm{i}}$ as per formula (1).

\section{Results and discussions}

The field tests of the designed procedure were conducted through comparison of formation pressure measured by any direct method (e.g. by bottom-hole pressure gauge) and the calculated formation pressure. This comparison was performed for the wells of the fields located in Samara Region. Moreover, we have done the selection of candidate wells using the following criteria:

1. The well was shifted from natural flowing operation to ESP operation. Prior to such shift they have performed formation pressure measurement using $\mathrm{BH}$ pressure gauge, as the formation pressure value was determined by direct measurement.

2 . The well prior its brining to production level was mandatory killed by process well-kill fluid. This condition is necessary to follow so as to exclude the errors related to evaluation of fluid density along the well-bore.

3 . The well was brought to its production level while monitoring the dynamic fluid level decrease in annulus.

4. The evaluation of formation pressure was done using the calculations based upon the plot showing the process of well brining to production level.

The Results of Comparison are presented in Table 1.

Table 1: Calculation Results for Formation Pressure

\begin{tabular}{|c|c|c|c|c|c|c|c|}
\hline \multirow{2}{*}{ Well } & \multirow{2}{*}{ Field Name } & \multirow{2}{*}{ Pay } & \multirow{2}{*}{ Reservoir Type } & \multicolumn{2}{|c|}{$\begin{array}{c}\text { Formation pressure, } \\
\mathrm{MPa}\end{array}$} & \multirow{2}{*}{$\begin{array}{c}\text { Difference in pressures } \\
\text { Pmeasured - Pcaclulated, } \mathrm{MPa}\end{array}$} & \multirow{2}{*}{$\begin{array}{c}\text { Relative } \\
\text { tolerance, } \%\end{array}$} \\
\hline & & & & Calculated & Measured & & \\
\hline 6 & Barinovsko-Lebiazhinskoye & Б2 & Terrigenous & 26.77 & 26.8 & 0.03 & 0.11 \\
\hline 8 & Barinovsko-Lebiazhinskoye & Б2 & Terrigenous & 26.62 & 26.80 & 0.18 & 0.67 \\
\hline 11 & Rakovskoye & $\mathrm{B} 1$ & Carbonate & 15.90 & 16.40 & 0.50 & 3.05 \\
\hline 15 & Gorkovskoye & B1 & Carbonate & 15.37 & 15.95 & 0.58 & 3.64 \\
\hline 16 & Zapadno-Shyrochenskoye & Д1 & Terrigenous & 33.90 & 33.30 & -0.60 & -1.80 \\
\hline 20 & Subbotinskoye & A4 & Carbonate & 20.86 & 21.01 & 0.15 & 0.71 \\
\hline 32 & Zimarnoye & Д3 & Terrigenous & 28.53 & 28.88 & 0.35 & 1.21 \\
\hline 35 & Sharlykskoye & B1 & Carbonate & 22.28 & 23.02 & 0.74 & 3.21 \\
\hline 54 & Grekovskoye & 52 & Terrigenous & 26.70 & 27.20 & 0.50 & 1.84 \\
\hline 63 & Verkhne-Vetlyanskoye & 52 & Terrigenous & 28.13 & 28.80 & 0.67 & 2.33 \\
\hline 64 & Alexeevskoye & $\mathrm{B} 2$ & Carbonate & 27.10 & 28.00 & 0.90 & 3.21 \\
\hline 64 & Evgenievskoye & A3 & Terrigenous & 14.41 & 14.50 & 0.09 & 0.62 \\
\hline 170 & Sudatovskoye & Двч & Carbonate & 21.06 & 21.90 & 0.84 & 3.84 \\
\hline 301 & Kuleshovskoye & A3 & Terrigenous & 16.42 & 17.01 & 0.59 & 3.47 \\
\hline 483 & Mikhailovsko-Kokhanskoye & $\mathrm{A} 0$ & Carbonate & 14.34 & 14.08 & -0.26 & -1.85 \\
\hline 701 & Kuleshovskoye & $\mathrm{A} 0$ & Carbonate & 17.89 & 17.20 & -0.69 & -4.01 \\
\hline 978 & Kuleshovskoye & Д3 & Terrigenous & 28.26 & 28.90 & 0.64 & 2.21 \\
\hline 1119 & Kuleshovskoye & A3 & Terrigenous & 17.55 & 18.06 & 0.51 & 2.82 \\
\hline
\end{tabular}


Results showing the comparison of measured and calculated formation pressure by the wells of the oil fields of Samara Region have illustrated their high convergence. The relative error in evaluating the formation pressure through the use of proposed procedure is within from $-4.33 \%$ to $3.84 \%$. The mean relative error makes $-/+2.39 \%$ and follows the allowable limits (-/+ 5\%). Figure 3 presents graphical convergence of these results.

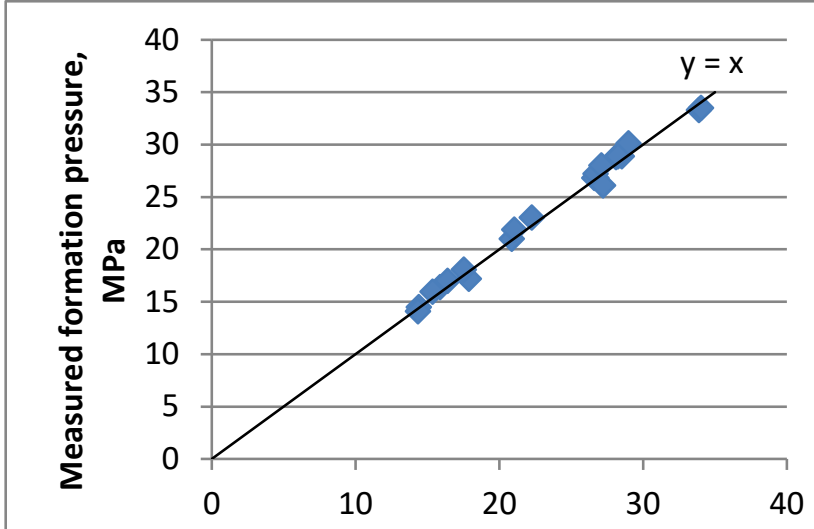

Calculated formation pressure, $\mathrm{MPa}$

Fig. 3: Measured Formation Pressure vs. Calculated Formation Pressure

As is seen in Fig. 3 the dependence of measured formation pressure versus calculated formation pressure is very close to equation $y=x$, that is another example of high convergence in results obtained.

The analysis of obtained results specific for each type of reservoir (Carbonate and Terrigenous) have not revealed the conformity in deviations between the calculated and measured results (Figs. 4 and 5). This is the good evidence for applicability in evaluating the formation pressure using presented procedure, both for Terrigenous and Carbonate reservoirs.

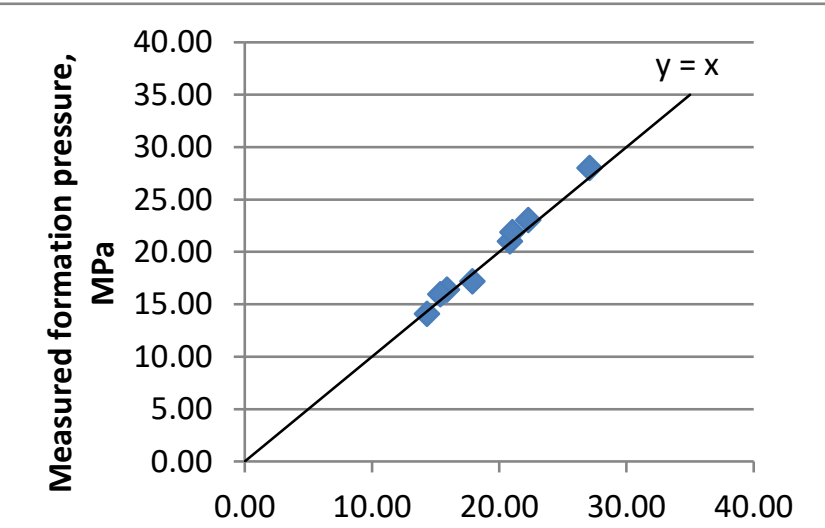

Calculated formation pressure, $\mathrm{MPa}$

Fig. 4: Measured formation pressure versus calculated formation pressure for the wells in Carbonate reservoir

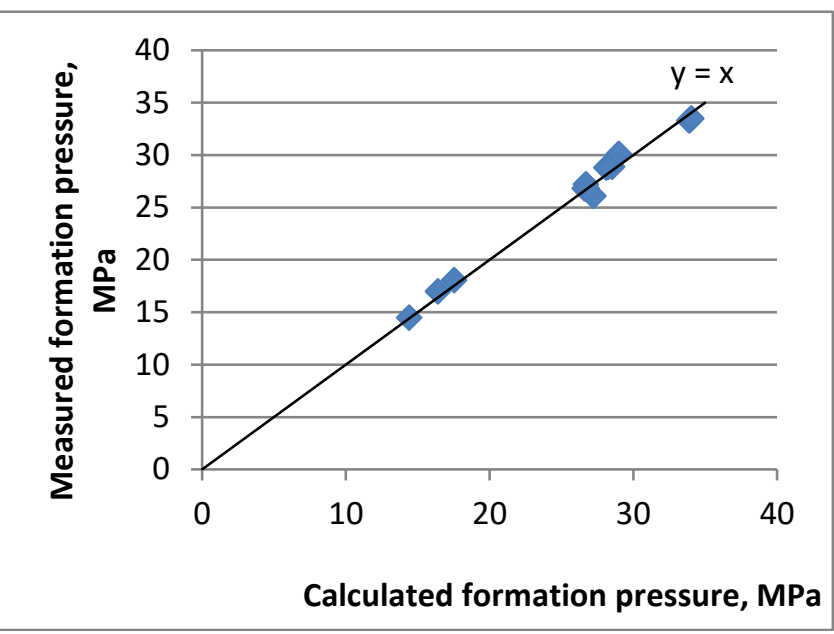

Fig. 5: Measured formation pressure versus calculated formation pressure for the wells in Terrigenous reservoir

\section{Conclusion}

1) The paper presents the designed procedure to evaluate formation pressure using well data at the stage of brining a well to its production level.

2) The procedure proposes to measure formation pressure only in wells equipped with ESP.

3) The procedure may be used only in cases when the well was killed prior its brining to production level.

4)The procedure was field tested at oil wells in Samara Region. The results related to the comparison of calculated and measured (by bottom-hole pressure gauge) values of formation pressure have shown that the relative error in evaluation of this formation pressure make $-/+2.39 \%$ (in average) and are within the allowable limits $(-/+5 \%)$.

\section{Nomenclature}

$\mathrm{p}_{\mathrm{w}}$ - bottom-hole pressure, $\mathrm{Pa}$

$\mathrm{p}_{\mathrm{i}}$ - formation pressure, $\mathrm{Pa}$;

$\rho_{(\mathrm{k} . \mathrm{f})}$ - kill fluid density, $\mathrm{kg} / \mathrm{m}^{3}$;

$\mathrm{H}_{\mathrm{r}}$ - reservoir depth, m;

$\mathrm{H}_{\mathrm{d}}{ }^{*}$ - the dynamic level at which the reservoir fluid inflow starts $\mathrm{t}_{\mathrm{o}}$ appear, m;

$\mathrm{t} *$ - the time of inflow start, sec.;

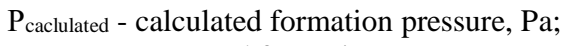

$\mathrm{P}_{\text {measured }}$ - measured formation pressure, $\mathrm{Pa}$;

$\mathrm{t}_{1} ; \mathrm{H}_{1}$ - coordinates of point 1 , sec, $\mathrm{m}$, respectively;

$\mathrm{t}_{2} ; \mathrm{H}_{2}$ - coordinates of point 2, sec, $\mathrm{m}$, respectively;

$\mathrm{t}_{3} ; \mathrm{H}_{3}$ - coordinates of point 3 , sec, $\mathrm{m}$, respectively;

$\mathrm{t}_{4} ; \mathrm{H}_{4}$ - coordinates of point 4 , sec, $\mathrm{m}$, respectively.

was field tested at oil wells in Samara Region. The results related to the comparison of calculated and measured (by bottom-hole pressure gauge) values of formation pressure have shown that the relative error in evaluation of this formation pressure make $-/+$ $2.39 \%$ (in average) and are within the allowable limits $(-/+5 \%)$.

\section{Subscript}

ESP - electric submersible centrifugal pumps

BH - bottom-hole 


\section{References}

[1] S.M. Aliev, G.T. Vartumyan, O.I. Davydov, "Evaluating Formation Pressure at the Basis of Identification Procedure", Oil and Gas, no. 2, pp. 36-38, 1978/

[2] K. G. Bagirov, R. A. Aliev, "Express Method to Evaluate Formation Pressure", Oil Industry, no. 2, pp. 41-44, 1969.

[3] V. I. Bakardzhieva, "Evaluation of Formation Pressure at the Basis of Functions with Flexible Structure", Azerbaijan Oil Industry, no. 9, pp. 41-43, 1982

[4] B. A. Bogachev, "New Procedure to Evaluate Formation Pressure", Bulletin of Higher Educational Institutions: Oil and Gas, no. 10, pp. 43-45. 1961.

[5] V. N. Vasilievskiy, "Set of Hydro-dynamic Reservoir and Well Studies to Get the Initial Data Necessary for Designing and Development", Papers of VNII, Gosttechizdat, issue 33, pp. 182-189, 1961

[6] V. N. Vasilievskiy, E. L. Leybip, "Evaluation of Formation Pressure", Oil Industry, no. 12, pp. 26-30. 1956.

[7] S. D. Mustafaev, "New Procedure to Evaluate Formation Pressure in Deep Pumping Wells", Oil Industry, no. 8, pp.39-42, 1968.

[8] I.A. Nasrullaev, E.I. Petrushevskiy, "Methods to Evaluate Current Formation Pressure by Initial Sector in Pressure Build-up Curves", Azerbaijan Oil Industry, no. 9, pp. 17-19, 1990.

[9] A.I. Osadchiy, A. Ya. Dymchenko, V. G. Berezin, "On Evaluation of Dynamic Formation Pressure and Saturation Pressure", Oil Industry, no. 3, pp.35-37, 1975.

[10] P. K. Stradymov, "Evaluation of Formation Pressure without Wel Shut-Down", Bulletin of Higher Educational Institutions: Oil and Gas, no. 3, pp. 45-50, 1966.

[11] G.A. Khalikov, "Evaluation of Formation Pressure through Measurements at the Depths Higher than Saturation Pressure", Oil Industry, no. 9, pp. 47-53, 1958.

[12] A.I. Tjunkin, T.M. Muhametzjanov, I.S. Ignatov, P.T. Im., "Reservior pressure mapping method based on well test and production data applied to Verh-Tarskoe oil field", Oil Industry, no. 5, pp. 6669. 2009.

[13] H. An, S.L. Scott, J.P. Langlinais, "Estimation of Bottomhole Pressure in Pumping Oil Wells: Effect of High-Viscosity Fluids and Casinghead Pressure", SPE Annual Technical Conference and Exhibition, 1-4 October 2000, Dallas, Texas.

[14] M.M. Khasanov, R.A. Khabibullin, T. Musabirov, S. Sokolov, V.A Krasnov, "Express Method to Estimate Target Bottomhole Pressure in Pumping Oil Well", SPE Russian Oil and Gas Exploration \& Production Technical Conference and Exhibition, 14-16 October 2014, Moscow, Russia

[15] A.R. Hasan, C.S. Kabir, "Determining Bottomhole Pressures in Pumping Wells", Society of Petroleum Engineers Journal, vol 25, pp. 823-838, 1985.

[16] R. S. Andriasov, I. T. Mischenko, A. I. Petrov et al., "Reference Guide-book on Oil Field Wells Designing and Operation. Oil production.Edited by Sh. K. Gimatudinov", M.:Nedra, 455 pp., 1983.

[17] G. Z. Ibragimov, N. I. Khisamutdinov, S. V. Muravlenko, V. N. Artemiev, A. R. Latypov, A. G. Telin, T. A. Ismagilov, "Oil Field Development.Volume 2 - Operation of Production and Injection Wells",M.:VNII on Organization, Management and Economics in Oil and Gas Industry, 137 pp., 1994.

[18] K. B. Korolev, T. N. Silkina, E. V. Pugachev, "Analysis of Adaptive Algorithm Application to Recalculate Bottom-hole Pressure as per Well-head Metering Data in Artificial Wells", Oil Industry, no. $11,2006$.

[19] V. N. Koskov, B. V. Koskov, "Evaluation of Fluid Density in the Annulus of Artificial Wells, Operated in Conditions of Releasing Annulus Pressure into Flowlines", Geology, Geophysics and Development of Oil and Gas Field, no. 10, pp. 57-60, 2007.

[20] I. T. Mischenko, "Calculations in Oil Production: Work-book for Colleges", M.:Nedra, 245 pp., 1989.

[21] I. T. Mischenko, "Calculations in Oil and Gas Production", M: Oil and Gas, 296 pp., 2008.

[22] I. T. Mischenko, "Oil Production by Wells", M: Oil and Gas, 826 pp., 2007.

[23] I. T. Mischenko, "Oil Production by Wells: Work-book for Higher Educational Institutions", M: FGUP"Oil and Gas", Publishers at I M. Gubkin Russian State Oil and Gas University, 816 pp., 2003.

[24] I. T. Mischenko, T. B. Bravicheva, A. I. Ermolaev, "Selection of Oil Well Production Type to Operate Hard-to-Recover Reserves", M.:FGUP "Oil and Gas" Publishers at I. M. Gubkin Russian State Oil and Gas University, 448 pp., 2005.
[25] L. N. Balandin, O. A. Gribennikov, "Study of Fluid Density Distribution in Well Annulus While Brining a Well to Its Production Level", Territory of Oil and Gas, no. 3, pp. 86-88, 2013. 